
identités professionnelles $\left(X X^{\mathrm{e}}-\left.\mathrm{XX}\right|^{\mathrm{e}}\right.$ siècle)

\title{
Brejon de Lavergnée (Matthieu), Histoire des Filles de la charité
}

Paris : Fayard, 2011, 690 p.

\section{Véronique Castagnet-Lars}

\section{(2) OpenEdition \\ Journals}

\section{Édition électronique}

URL : https://journals.openedition.org/histoire-education/2980

DOI : 10.4000/histoire-education.2980

ISSN : 2102-5452

Éditeur

ENS Éditions

Édition imprimée

Date de publication : 31 décembre 2014

Pagination : 245-246

ISBN : 978-2-84788-651-1

ISSN : 0221-6280

\section{Référence électronique}

Véronique Castagnet-Lars, "Brejon de Lavergnée (Matthieu), Histoire des Filles de la charité ", Histoire de l'éducation [En ligne], 142 | 2014, mis en ligne le 31 décembre 2014, consulté le 20 mai 2021. URL : http://journals.openedition.org/histoire-education/2980; DOI : https://doi.org/10.4000/histoireeducation. 2980 


\title{
Notes critiques
}

\author{
BREJON de LAVERGNÉE (Matthieu) \\ Histoire des Filles de la charité \\ Paris : Fayard, 2011, 690 p.
}

L'apport de cet ouvrage en histoire de l'éducation est important car il ne s'agit pas d'une simple monographie en histoire religieuse consacrée aux Filles de la charité. Matthieu Brejon de Lavergnée choisit comme sujet d'étude une congrégation séculière d'Ancien Régime fortement impliquée dans l'instruction à divers titres.

Ni religieuses, ni femmes mariées, les Filles de la Charité ont une finalité missionnaire et universelle : elles prodiguent des soins corporels aux malades et s'assurent de leur démarche eschatologique. La fondation de la congrégation - fondation placée sous le sceau du pragmatisme et dans un contexte de forte concurrence, puisque dans les années 1590-1610 naissent aussi les ursulines du Comtat Venaissin, les Filles de Notre-Dame de Jeanne de Lestonnac à Bordeaux, les jésuitesses de Mary Ward par exemple - et l'analyse de leurs actions menées au quotidien avec "la rue comme cloître" (Vincent de Paul), donnent aux chercheurs de nouveaux éclairages sur la déclinaison au féminin de la réforme catholique. La mise en perspective historique - de la fondation de la confrérie au milieu du XVII ${ }^{e}$ siècle à la suppression de la congrégation en 1792 (décret du 18 août contre les congrégations séculières) - permet aussi de mieux saisir les inflexions, les difficultés de gouvernement, les modifications du recrutement des Filles, la nécessaire adaptation à un contexte social et économique changeant.

Ce faisant, quand elles s'attachent au soin des enfants abandonnés, aux pauvres criminels, aux forçats, aux pauvres malades, aux vieillards de l'hospice, les Filles de la Charité développent et transmettent de génération en génération des pratiques médicales. Leur savoir-faire en la matière est des plus précieux. En outre, elles proposent d'enseigner dans les petites écoles paroissiales, dans 
les manufactures et ouvroirs des hôpitaux, dans les hôpitaux d'enfants trouvés. Ainsi, le succès de cette congrégation et l'accroissement de ses fondations illustrent en réalité la demande croissante d'instruction par les fidèles sujets du roi de France.

L'auteur présente les résultats de sa recherche dans cet ouvrage, composé de onze chapitres. Les trois premiers relatent la vie des principales personnalités impliquées dans les débuts de cette fondation : Vincent de Paul (mort en 1660), Louise de Marillac (1591-1660), Marguerite Naseau (1594-1633). Elles inspirent la spiritualité de ces séculières mystiques et actives, décrite dans le chapitre VIII. Viennent ensuite quatre chapitres sur le fonctionnement de cette congrégation (chapitres IV à VII), avant d'envisager son rayonnement à l'échelle du royaume de France (chapitres IX et X). Le dernier chapitre présente les actions menées en faveur des pauvres.

À la fin de chacun, l'historien publie, après transcription ou traduction, des documents originaux découverts dans les fonds de la congrégation, portant alors à la connaissance des lecteurs quelques pièces significatives parmi toutes celles qu'il a pu consulter dans les fonds privés en particulier. En effet, la documentation consultée est considérable et inédite à ce jour. Pour le plus grand bonheur des chercheurs en histoire de l'éducation, Matthieu Brejon de Lavergnée nous en propose une synthèse historienne de grande qualité.

Véronique Castagnet-Lars

SAVOIE (Philippe)

La construction de l'enseignement secondaire (1802-1914), Aux origines d'un service public

Lyon : ENS Éditions, 2013, 501 p.

L'enseignement secondaire français au XIX ${ }^{\mathrm{e}}$ siècle avait déjà fait l'objet de belles et amples études, telles celle de Clément Falcucci sur L'humanisme dans l'enseignement secondaire et celle de Paul Gerbod sur La condition universitaire. Et pourtant, dans cet ouvrage issu de son travail d'HDR, Philippe Savoie révolutionne véritablement nos connaissances, non seulement parce qu'aux approches thématiques des études précédentes, il ajoute des considérations financières et budgétaires qui avaient rebuté la plupart des historiens, mais 